\title{
Cause analysis of low collection rate of Chinese waste paper
}

\author{
H. Feng \& S. Tomonari \\ Graduate School of Environment and Energy Engineering, \\ Waseda University, Japan
}

\begin{abstract}
As waste paper is gradually becoming an important material in paper making with the calling for promoting a sustainable society, waste paper reuse comes to be an important issue nowadays. The collection rate is an index to measure the effectiveness of the domestic collection of waste paper resources used for recycling. Countries likes Germany, Korean, Japan, lead in this field. However, the Chinese collection rate is very low compared with these developed countries. This paper tries to figure out the real reasons behind such phenomenon by analyzing a case of Xishui County in Central China based on a series of field research and interviews. It is found that the recycling behaviours of households are driven by money, and the main reason for none-recycling is the inconvenience of the recycling service and facilities. Also it appears that age is significantly correlated with recycling frequency, and old people tend to more actively engage in paper recycling. Subsequently, related plans are proposed and finally evaluated.

Keywords: waste paper, collection rate, paper recycling, cause analysis, China, case study.
\end{abstract}

\section{Introduction}

Paper recycling is gradually becoming a hot issue in developing countries nowadays and greatly helps in building a circular economy to promote a sustainable society. It will reduce energy consumption by $40 \%$ (Energy information administration claims) [1] or by 64\% (Bureau of International Recycling claims) [2] and drawdown the use of landfill (Recycling 1 ton of 
newspaper eliminates 3 cubic meters of landfill) [3], and lessens 35\% water pollution and $74 \%$ air pollution [4].

In recycling, the collection rate is an important index to circulate the actual effectiveness of resource collection before running into utilization procedure. Currently, collection rates of waste paper differ among countries, varying between $21 \%$ and $91 \%$ in 2009 [5]. Generally speaking, the rate is relatively lower in developing countries. The Chinese waste paper collection rate is low, compared with South Korea, Germany, and the UK. The rate in China was 45.74\% in 2010 (by the end of 2010) [6]. However, situations differ in areas. In the eastern part of China, the economy is more developed and the collection rate is higher than other regions. In contrast, the western region is relatively poor in economy as well as collection rate, especially in the rural villages, and the situation in central areas is moderate [7].

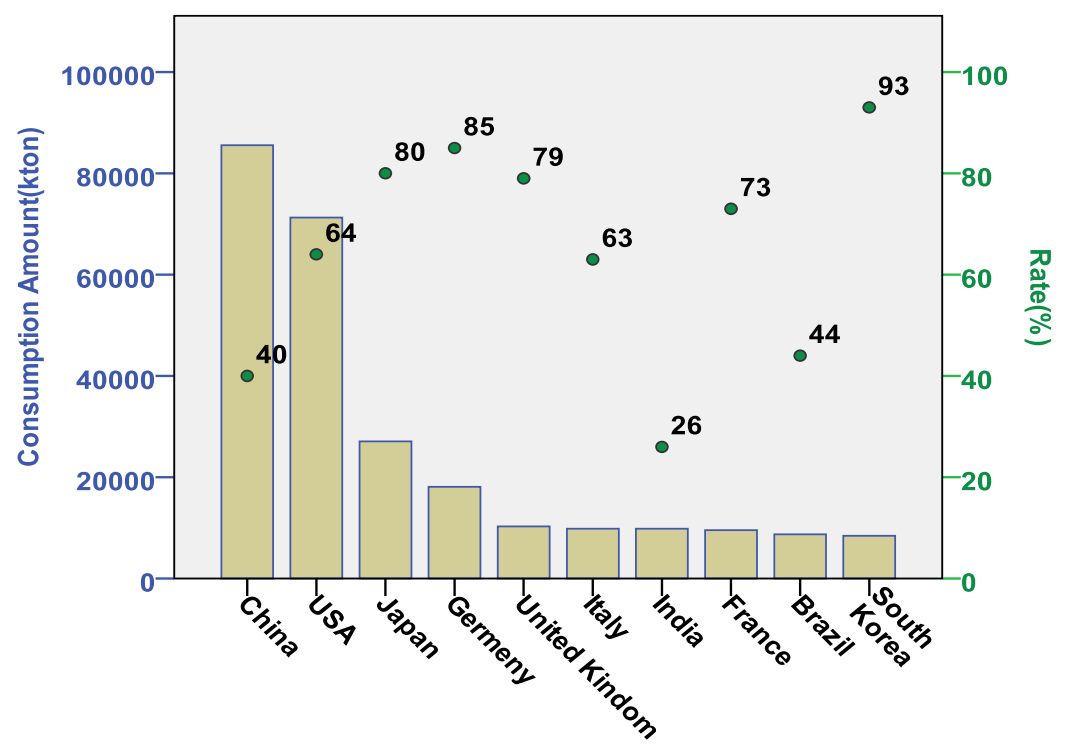

Figure 1: $\quad$ Collection rate of waste paper in countries (year 2009) [8].

This paper is a part from one chapter of one of the author's doctoral thesis "Analysis of Low Collection Rate of China's Waste Paper Resources from Policy Aspect". The idea is to find three different cases - Eastern Metropolis, Central County, Western village - in China to analyse the collection rate situation and the reasons for low collection according to the "Three Region" view, which was first proposed in the nation's seventh five-year plan to demarcate economic regions in China in 1985 [9], and is still commonly used now. The division is at the most advanced region; the east coast, and followed by the central region and the poorest; the western region. As far as waste paper collection is concerned, the situation is different in regions. Not only is there a huge economical gap between the eastern and western parts of China, but also there is a great difference of 
income between the rural and urban areas inside each region. This calls for further dividing into the metropolis in the eastern region, county in the central region and village in the western region for the research.

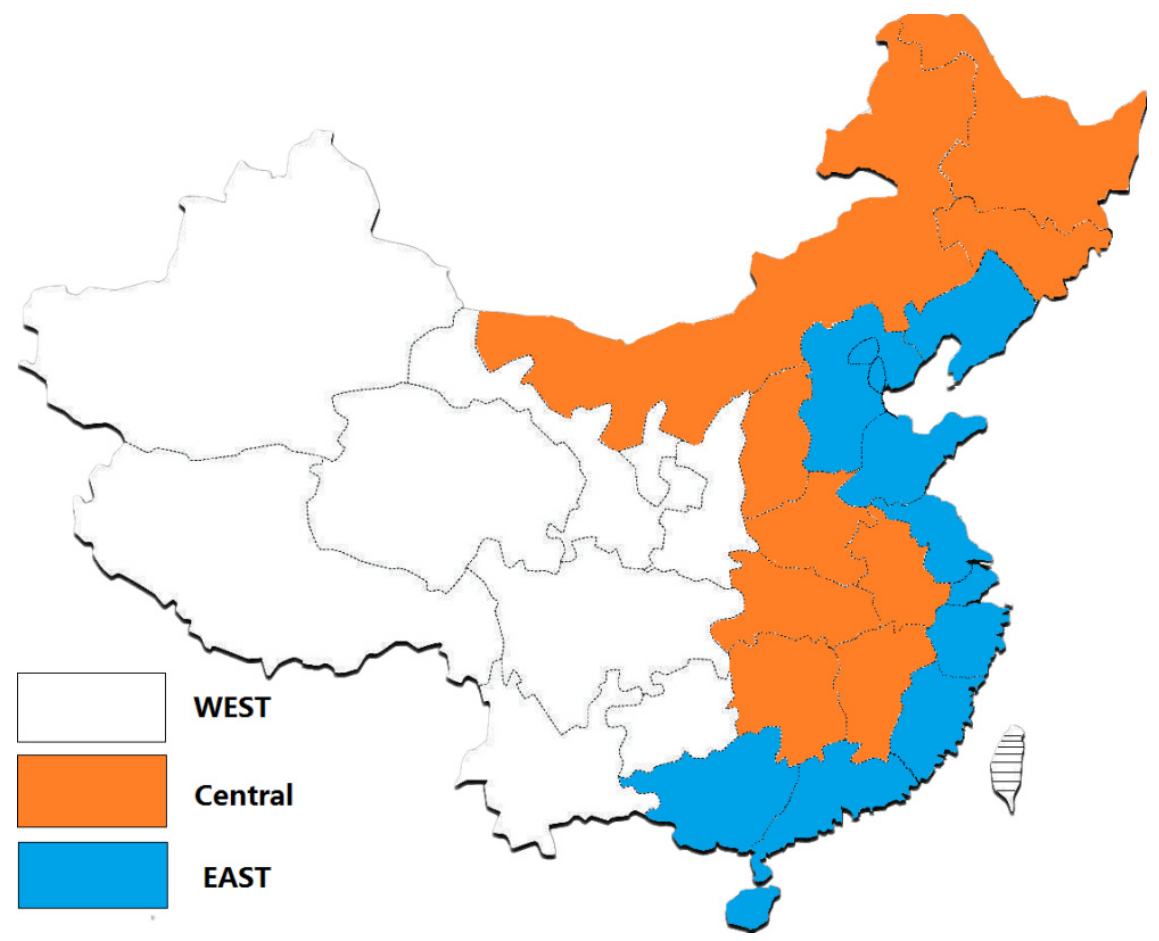

Figure 2: “Three Regions” divisions of China.

Xishui is the selected case representing counties in the central part of China, firstly because it is the central area in the central region. It is called the "Water and Land Hub" of eastern Hubei Province, and has location superiority. Secondly, because its economical level is, on average, far away behind big cities but better than small villages in the central region. It is strong for its agriculture and the primary industry takes up to $37.13 \%$ of the whole county's economy. Nowadays, the secondary industry is experiencing a rapid development. The gross domestic production per capita is 8,226 RMB in 2008. The permanent population was 872,650 in November 2010.

\section{Waste paper recycling situations}

Interviews were taken at local government administrations, companies, former industry associations and schools in February 2012, sponsored by the International Environment Leader program of Waseda University [10]. 
Unlike developed countries, there are no special statistics about waste paper recycling situation in China. To find the Chinese waste paper collection rate, especially in inland counties, it's more difficult. The waste paper collection rate in the county is estimated at $45 \%$ by professionals.

\subsection{Recycling cultures}

In Xishui County, most household recyclable paper is thrown away sporadically. Recycling only occurs among people who want to sell waste paper and waste paper trade agencies. Waste paper becomes tradable merchandise and recycling turns out to be an economic behaviour in the local area. Lack of knowledge of waste recycling results in a lot of waste paper being mixed with other refuse and dumped outside. This is consistent with the local waste disposal channel. Large proportions of waste mixed with household waste paper are discarded on the street. Sanitation workers are generally divided into 2 people a team. One street has two teams. Teams have two shifts in one day. The garbage truck will come to the working street four times a day, deliver waste to the nearly mid-point (in total 7). Waste is gathered there and is transport to the only landfill site in the county.

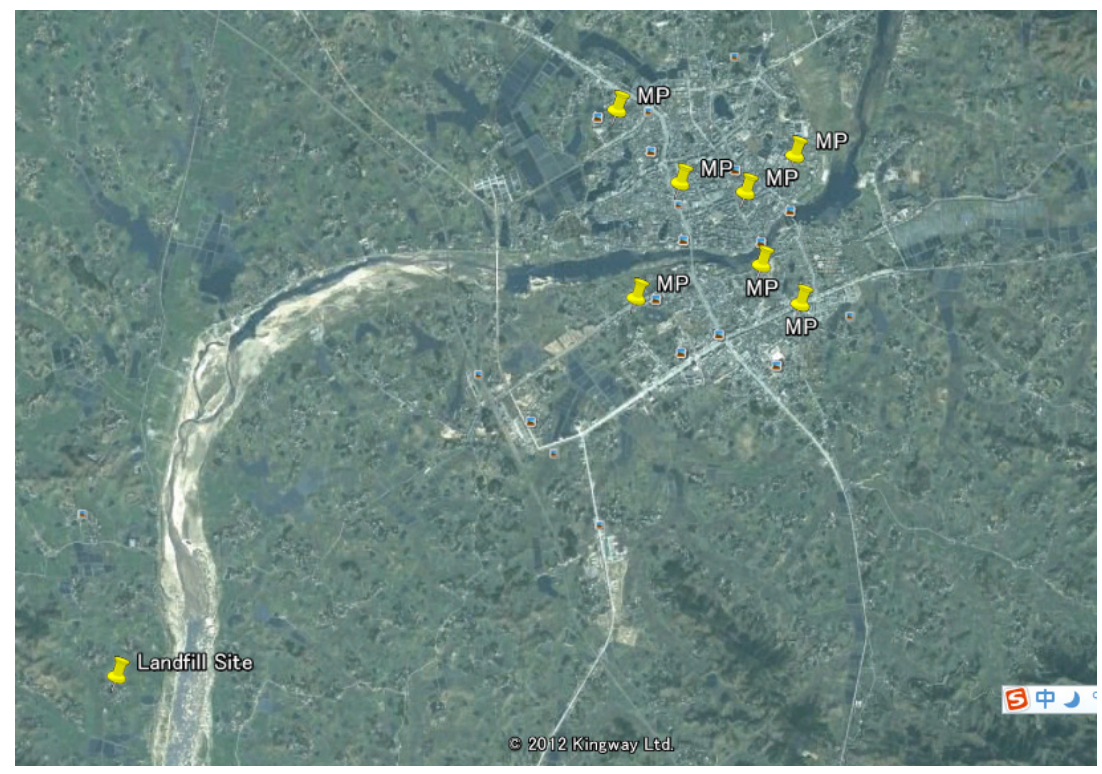

Figure 3: $\quad$ Waste disposal network in Xishui County [11].

Local government has no awareness of paper recycling; there is no requirement for local paper recycling; there are no statistics of waste paper collection, no regulations, and no public recycling facilities. In fact, there is a resource reuse association in the county, but it is established by a local supply 
agency (collectively owned company), and huge attention is paid to metals rather than paper.

\subsection{Waste paper flow}

Waste paper generates from offices, schools, households, department stores and streets. Waste paper in offices, schools, and stores is collected by collecting companies. As far as household waste paper is concerned, some is collected by companies, but a large proportion is discarded on curb sides. Other street waste paper is mainly paper packages, and leaflets thrown by pedestrians.

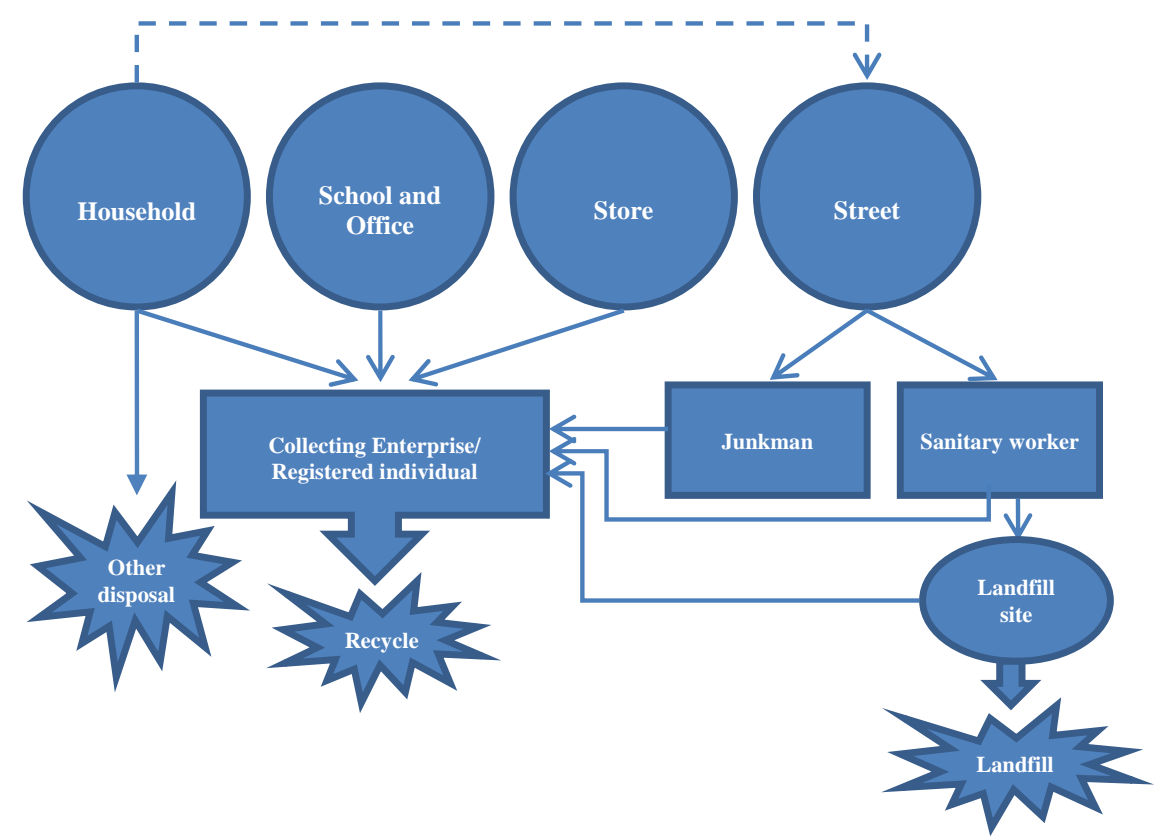

Figure 4: Waste paper flow in Xishui county.

The local waste paper collection presents a "pull-push" model. Waste paper principally generates from houses, schools, offices and department stores. Waste paper in schools, offices, stores are in a huge amount, of good quality and the collection is more intensive and convenient. Benefit drives collecting companies and individuals wild about onsite acquisition. However, collecting from households is more sporadic, costly, lower quality, so it is less attractive to collecting companies. Although local households are willing to have their waste to be sold, a lot is dumped on curb sides, seldom recycled, and are mainly mixed in with the other rubbish and go to landfill as there are no incineration facilities in the county. 


\subsection{Waste paper businesses}

There are 6,872 tons of recovered paper resources amounting to 4.81 million RMB (estimated in 2005) according to the "Report of Renewable Resource Industry in Xishui County (Aug. 2006)” [12].

No company specializes in paper collecting. According to the data given by the Registration Branch, Xishui County, there are 248 privately owned enterprises and 100 self-employed individuals registered to run recycling businesses in Xishui County. However, there is no classified information on each field, like paper, metal, etc. No companies specialize in paper collecting; they all have a comprehensive collecting range, usually including metals, machinery, electronics and plastics [13].

In addition, it is easy to enter into the business, because low knowledge and start up capital is required. There are two kinds of people engaging in the waste paper collecting business; one is the people who have no business license, and are mostly lowly-educated. The other is the enterprise scale. Normally, it is cheap to start the business; only 10,000 to $20,000 \mathrm{RMB}$ are needed for the capital turnover at the initial stage, according to Mr Qiushi Chai, the president of Xinfa Renewable Resources Company and former chairman of Resources Recycling Association of Xishui County.

There is a strong necessity of improving the governmental service. One can hardly tell who is running a waste paper collection business from the information on the registration database and a lot of information is missing. Registration items required in the form are, for a privately owned enterprise: registration level, name of enterprise, address, registration capital, scope of business, registration authority, jurisdiction authority, legal representative, establishment date; for the individual, a telephone number, bank account, fixed capital, working capital, employee, nationality and political status are added. But almost all of these detailed items are left blank. 61.39\% of the self-employed are currently in the term of validity, which implies the data still needs updating. The validity date shows that privately own companies last longer than self-employed individuals.

Collecting companies are mostly small scale; since for both privately owned enterprises and individuals, registration capital is not a must. $10.08 \%$ of privately owned enterprises, their registration capital (although $22.98 \%$ of the companies' information is missing) is more than 0.5 million RMB, which is a big scale by county level, for $18.81 \%$ of individuals, the fixed assets are greater than 0.1 million.

\subsection{Summary}

Waste paper collecting is neither a spontaneous obligated activity nor a mandatory activity regulated by the local administrations. High cost, and inconvenient channel leads household recyclable paper to become mixed with garbage dumped on the street, finally going to landfill. There are no companies specializing in paper recycling. It is easy to enter the local recycling business; people running these businesses are mostly self-employed; enterprise scales are 
small. Awareness should be aroused to improve the administrative service and enhance paper recycling related regulation.

\section{Questionnaire survey of household waste paper collection}

The questionnaires were designed to survey local households on waste paper collection in Xishui County. The questions were mainly about the residents' attitude towards waste paper collection and their collection activities, and were taken among the local residents living in downtown of Xishui County.

Among 50 questionnaires (one is invalid), there were 28 men (57.14\%) and 21 women (42.86\%). Age range was from 10 to 81; the median age being 39 . The level of education was divided into 4 levels: primary school or below (6); middle school (5); senior high (11); college or above (27), which were $12.24 \%$, $10.20 \%, 22.45 \%$, and $55.10 \%$ respectively.

\subsection{Awareness}

When asking the question "Do you think waste paper is a kind of resource and can be reused?” $79.59 \%$ of people answered “yes”, while $21.41 \%$ of people said they don't have such kind of awareness. However, when combining it with the previous question, there are actually $65.31 \%$ of people who have recycling activities (including $4.08 \%$ of people who either mix throw or wait for home acquisition). So why do $14.28 \%$ have consciousness to recycle but end up with non-recycling activities? Do they cheat on the question or just have another reason behind the situation?

\subsection{Behaviours}

When answering the question, "How often do you usually do paper recycling?" 46.94\% people answered "sometimes", 24.49\% said "always", 16.33\% replied "seldom", and $12.24 \%$ answered "never". This shows that a large proportion of people say they are engaging in waste paper recycling "sometimes” or "always", and it seems a relatively high frequency.

When asked "Which ways of disposal do you choose for waste paper?" $55.10 \%$ of people said they wait for scrap collectors to have a door to door collection. However, $36.73 \%$ of people just mix waste paper with other garbage like food residue, plastic packages, and then throw it away. Minorities choose to directly sell to the waste product collecting station $(12.24 \%)$ or for incineration (4.08\%).

\subsection{Motivations}

With the question "What facilitates you to recycle paper?”, the largest proportion (52.02\%) gave the reason for recycling as being motivated by money - "sell for money and make profit" - followed by $48.98 \%$ of people give environmental concerns, and $34.65 \%$ are for saving resources. Still $6.12 \%$ of people replied that 
there is nowhere for them to throw, so they recycle, and $4.08 \%$ of people gave no answer.

People of no awareness who said that "waste paper are resources and can be reused" have recycling activities which are mostly economically motivated. Six out of 10 who don't recycle paper said they do it for money (60\%). And other reasons are environmental protection (30\%), saving resources $(10 \%)$, nowhere to throw (10\%), no answer (10\%).

The main reason that people don't achieve their recycling behaviours is that "they couldn't wait for the home acquisition collectors to arrive” (26.53\%); “the process of assortment is very troublesome" (24.49\%); "the acquisition price is low” (15.38\%); and “waste paper is garbage” (15.38\%).

The reason why people who have an awareness that "waste paper is a resource and can be reused" but who end up not pursing recycling is mainly because they "they couldn't wait for the home acquisition collectors to arrive" (30.77\%); "the process of assortment is very troublesome" (23.08\%). Other reasons are "the acquisition price is low" (7.69\%), and "waste paper is garbage" (10.26\%). In addition, 12 people didn't reply to this question (comprising $30.77 \%)$. By segmenting by frequency of recycling, among them, $41.67 \%$ are "sometimes" and $41.67 \%$ are "always". So it may be that the reason they are actually recycling frequently is there is no reason for them not to recycle.

\subsection{Influencing variables testing}

Taking "frequency” as the dependent variable y, "age”, "gender”, “education level" and "consciousness" as the independent variable $\mathrm{x}$, we found a strong correlation between "age" and "frequency", but no significant correlation between "gender" and "frequency", "education" and "frequency", and "conscious" and "frequency".

Table 1: $\quad$ Definition of variables.

\begin{tabular}{|l|l|l|}
\hline \multicolumn{1}{|c|}{ Variables } & \multicolumn{1}{c|}{ Definition } & \multicolumn{1}{c|}{ Description } \\
\hline Frequency $(\mathrm{y})$ & Numerical variable & $\mathrm{X}=1,2,3,4$ \\
\hline Age $\left(\mathrm{x}_{1}\right)$ & Numerical variable & $\mathrm{X}=1,2,3 \ldots$ \\
\hline Gender $\left(\mathrm{x}_{2}\right)$ & Dummy variables & $\mathrm{X}=0,1$ (0-“female”, 1-“male”) \\
\hline Education level $\left(\mathrm{x}_{3}\right)$ & Numerical variable & $\mathrm{X}=1,2,3,4$ \\
\hline Consciousness $\left(\mathrm{x}_{4}\right)$ & Dummy variables & $\mathrm{X}=0,1$ (0-“not have”, 1-“have”) \\
\hline
\end{tabular}

Table 2: $\quad$ Regression of coefficient.

\begin{tabular}{lcccc}
\hline & Coefficients & Standard Error & t Stat & P-value \\
\hline Intercept & 1.177128 & 0.659507493 & 1.784859 & 0.081179 \\
Age & 0.0307588 & 0.011805094 & 2.605554 & 0.012468 \\
Gender & -0.302278 & 0.283012712 & -1.06807 & 0.291313 \\
Education level & 0.0690172 & 0.133761604 & 0.515972 & 0.608457 \\
Consciousness & 0.3871775 & 0.347453295 & 1.11433 & 0.271188 \\
\hline
\end{tabular}




\section{Proposal}

The main obstacle to paper recycling in the county is the problem of the inconvenience of waste paper acquisition from households. To solve this problem the motivations of collecting companies should be stimulated; that is to promote an intensive collection service. Not only will it help to improve paper quality, but also it might reduce inconvenience for households. Thus three plans are made based on the previous analysis and the pros and cons are given as follows.

\subsection{Plan A: government monopoly}

This refers to the local government enforcing a strict intensive collecting scheme. Drawing an example from Japan - specific acquisition in a fixed period. The Government unifies the whole collection. No money will be paid to households.

Advantage: extreme time and cost-saving; also effective. It will work well especially in the long run as the waste paper recycling reward gradually disappears.

Disadvantage: less effective in the short term because a lot of households are motivated by money No competition through the market may lead to inefficiency. It will also cause unemployment of most self-employed people in the business.

\subsection{Plan B: collecting company bidding}

This refers to adopting a contracting system, that is, a collection enterprise can bid a selected area to provide an intensive collection service under governmental control.

Advantage: good for collecting companies; they are more efficient and effective because of the possibility of launching an intensive collection in which they won the bidding.

Disadvantage: regional monopoly will lead to a loss of consumer surplus, and it will finally lead to fewer collections in the long run. It will cause unemployment of most self-employed people who are currently engaged in the business.

\subsection{Plan C: government accommodation}

Make accommodative policy for enterprises to establish a door-to-door acquisition or other convenient recycling logistics and facilities by giving subsidies or making them tax free and so on. Then, after a certain time, back to normal, and let the market regulate itself.

Advantage: good for development of the industry and also employment and the livelihood of rag pickers; sustainable in the long run.

Disadvantage: seldom has an effect in the short run. 


\subsection{Other policies}

Policies that should accompany the proposed plan, such as prohibiting illegal dumping, implementing a waste paper grade and recycling classified standard, improving recycling facilities, like a Recycle Bin, creating a household recycle training program, increasing knowledge of recycling to the public, enhancing environment education since formative education period. Above all, local authorities should target younger generations as old people are actually the active paper recycling group.

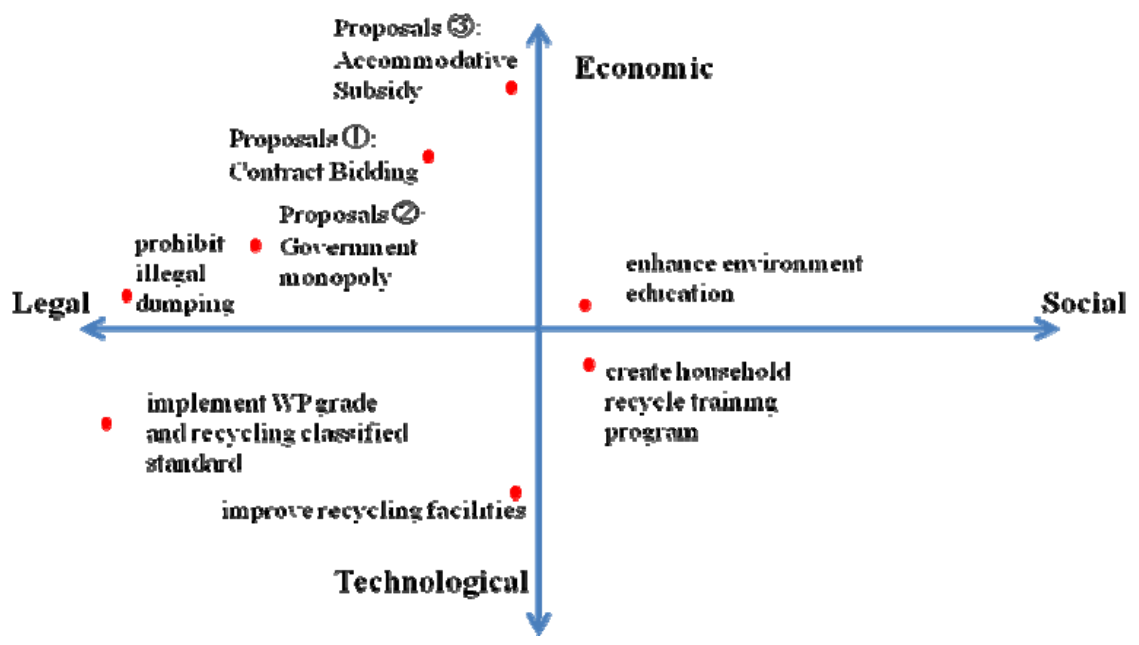

Figure 5: $\quad$ Proposals and policies.

\section{References}

[1] Energy Information Administration, Saving Energy Recycling Paper and Glass. Recycling Paper and Glass 2006(9).

[2] Bureau of International Recycling. Information about Recycling. September 27, 2007.

[3] Sudbury, Jodi B. 50 Simple Things You Can Do to Save the Earth. Berkeley CA: Earthworks Press 1989.

[4] US Environmental Protection Agency. Recycle on the Go: Basic Information. October 18, 2007.

[5] Paper Recycling Promotion Center. International recycling paper situation working papers 2010.March.

[6] China Paper Association (2011): Annual report of China Papermaking Industry in Year 2010, http://www.chinappi.org/.

[7] Weiliang Li, Measures toward paper recycle in Zhejiang Province. Chinese and Japanese Recovered Paper Seminar, October 11, 2011.

[8] Feng Hua, Tomonari Shinichi, Analysis of China's Current Waste Paper Collection Rate. ECO Design 2011 proceeding, pp. 852-855, 2011. 
[9] China State Council, Seventh Five-year Plan, October, 1985.

[10] Japan Science and Technology Agency, International Environment Leader program, http://www.jst.go.jp/shincho/en/program/kankyou.html

[11] Google Earth, 2012 Kingway Ltd, 2012 Mapabc.com, 2012 Cnes/Spot Image.

[12] Resources Recycling Association of Xishui County, Report of Renewable Resource Industry in Xishui County, August. 2016.

[13] Registration Branch of Industry and Commerce Administration Bureau of Xishui county, Information Inquiry System. 